\title{
Influence of Nano-CaCO3 Particles on Shear Strength of Epoxy Resin Adhesives
}

\begin{tabular}{|c|c|c|}
\hline \multicolumn{3}{|c|}{ Halil Burak KAYBAL ${ }^{1}$, Hasan ULUS ${ }^{* 2}$, Ahmet AVCI ${ }^{1}$} \\
\hline \multicolumn{3}{|c|}{$\begin{array}{l}{ }^{1} \text { Selcuk University, Faculty of Engineering, Department of Mechanical Engineering, TURKEY. } \\
{ }^{2} \text { Selcuk University, Huglu Vocational High School, TURKEY. }\end{array}$} \\
\hline Bașvuru/Received: 06/02/2017 & Kabul/Accepted: 11/04/2017 & Son Versiyon/Final Version: $15 / 06 / 2017$ \\
\hline
\end{tabular}

\begin{abstract}
Epoxy resins are a very common type of adhesive materials in several fields like the automotive industry, marine, probably the most important is in the aerospace industry. Adhesive joints of carbon fiber reinforced epoxy composite laminates are worked using an epoxy resin as the adhesive. In this paper, Adhesive joints were modified nano-CaCO3 in order to enhance the shear strength of epoxy adhesives. The enhancements of shear strength of epoxy adhesive joints reinforced with different nano-CaCO3 particles loading have been studied. The adhesive properties were measured by tensile lap shear test as a function of nano-CaCO3 amount and damaged adhesive surface roughness. Also, the fracture surfaces were examined with Scanning Electron Microscopy (SEM).
\end{abstract}

Key Words

"Adhesive; epoxy; carbon fiber; shear strength; nano-CaCO3" 


\section{INTRODUCTION}

Epoxy adhesives are commonly used in applications in aerospace, automotive, marine and construction industries due to their adhesive strength, durability and toughness, chemical resistance, ease of application (Lu, 2000; Jeong, 2005; Jiang, 2005; Tan, 2006; Tee, 2007; Zhrang, 2016). Recently, the mechanical properties enhancement of the epoxy adhesives has been performed by the use of nanoparticle reinforcement such as nano-rubber particles, carbon nanotubes, graphene and silver nanowires, nano-clay, alumina and silica nanoparticles (Khoee, 2010; Sydlik, 2013; Fu, 2014; Wu, 2006; Xian, 2006; Kim, 2013; Ulus, 2016). Enhancement of tensile properties of epoxy adhesives is important due to the adhesively bonded joints in a structure generally subjected to a combination of tensile and shears loads (Murakami, 2015). While there are many research on the nanoparticle filled epoxy adhesives, there are few research about nano $\mathrm{CaCO} 3$ epoxy adhesives. Furthermore, since no publications were found in literature related to the carbon fiber $(\mathrm{CF})$ reinforced epoxy laminated composites adhesive joining, this study was performed.

The present work aimed to improve adhesive joining of Epoxy/CF laminated for use in the above mentioned fields. For this purpose, firstly Ep/CF laminated composites were produced via (Vacuum Assisted Resin Infusion Method) VARIM and for prepare the shear lap test specimens. Also, modification of epoxy resin investigates with tensile tests as dog bone specimens.

\section{EXPERIMENTS}

The epoxy resin as the commercially available diglycidylether of bisphenol-A (DGEBA) supplied by Momentive Hexion Inc. Nano-CaCO3 was purchased from Mk Nano Co. The average particle size of nano-CaCO3 was $40 \mathrm{~nm}$ (as can be seen in Fig. 1). Carbon fiber fabric and the all other vacuum infusion equipments were provided by Dost Kimya Inc., Turkey. The area density of carbon fiber was $300 \mathrm{~g} / \mathrm{m} 2$ and each bundle consisted of 12000 filament.

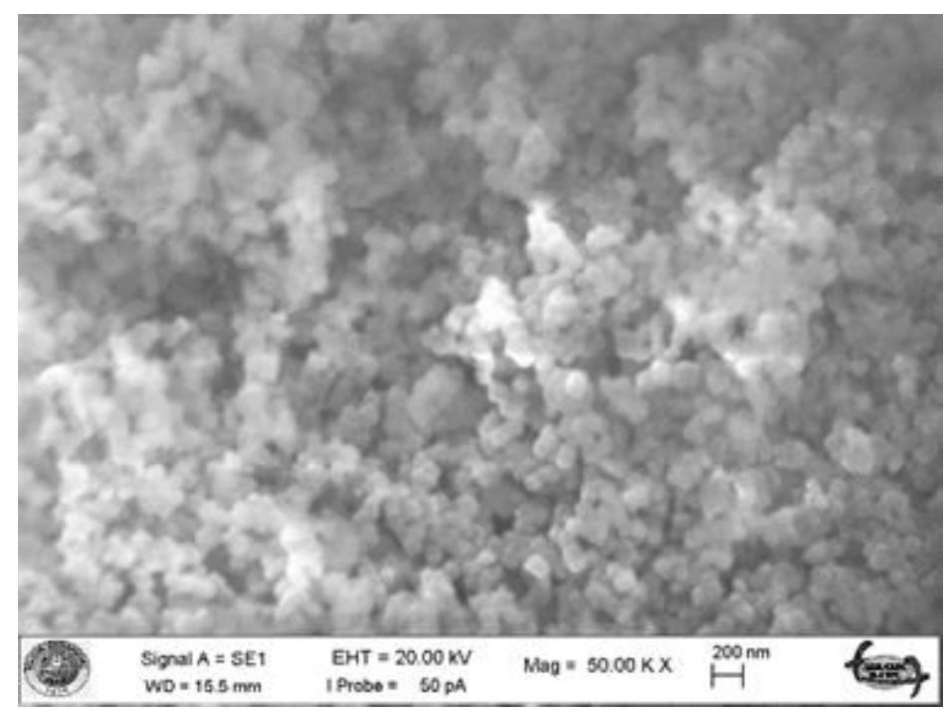

Fig. 1. SEM images of nano-CaCO3

\subsection{Preparation of nano-CaCO3-Epoxy composites}

The nano-CaCO3 weight content was range from 1 to $5 \mathrm{wt} \%$. The epoxy and nano-CaCO3 were stirred for 30 min with an ultra sonicator. Curing agent was added after dispersing process in epoxy and degassed at $25{ }^{\circ} \mathrm{C} / 0.6$ bar for 20 min. The steel mold covered with release agent and mixture was poured into preheated mold. Curing was performed at $80{ }^{\circ} \mathrm{C} \mathrm{for} 1 \mathrm{~h}$, at $120^{\circ} \mathrm{C}$ for $2 \mathrm{~h}$ and then it was slowly cooled to room temperature in the oven. All samples were removed from mold and conventionally polished with $\mathrm{SiC}$ sandpapers with grit numbers of 800 to minimize effect stress concentration caused by sharp edges.

\subsection{Preparation of nano-CaCO3-Epoxy/CF composites}

Carbon fiber reinforced epoxy laminated nanocomposites were prepared by means of VARIM (Ulus and Avci, 2015). Then, the cured panel was taken out and specimens were cut according to Standard Test Method for Lap Shear Adhesion for Fiber Reinforced Plastic Bonding (ASTM D5868-01) standards. All samples polished with SiC sandpapers identically.

\subsection{Preparation of nano-CaCO3-Epoxy/Adhesives}

Firstly prepared specimens according to the recommended dimension $(100 \mathrm{~mm} \times 25.4 \mathrm{~mm} \times 0.76 \mathrm{~mm})$ were abraded with silicon carbide paper to roughen the adhesive surfaces then degreased with acetone to remove any dust and dry at $35^{\circ} \mathrm{C}$ for 10 min. The 
nano-adhesives were prepared by addition of epoxy resin to achieve 1, 2, 3, 4 and $5 \mathrm{wt} \%$ nano-CaCO3 content, which were then mixed via ultra sonicator for $30 \mathrm{~min}$ and degassed in a vacuum oven $25^{\circ} \mathrm{C} / 0.6$ bar for $20 \mathrm{~min}$. Then the hardening agent was added into the mixture according to supplier instructions. The adhesive area was signed as $25.4 \mathrm{~mm} \times 25.4 \mathrm{~mm}$. The schematic view of the samples was given in Fig. 2. The nano-adhesive mixture was applied on the adhesive area on both piece and pressed down via clamp. The adhesive was cured at $80^{\circ} \mathrm{C}$ for $1 \mathrm{~h}$, at $120^{\circ} \mathrm{C}$ for $2 \mathrm{~h}$.

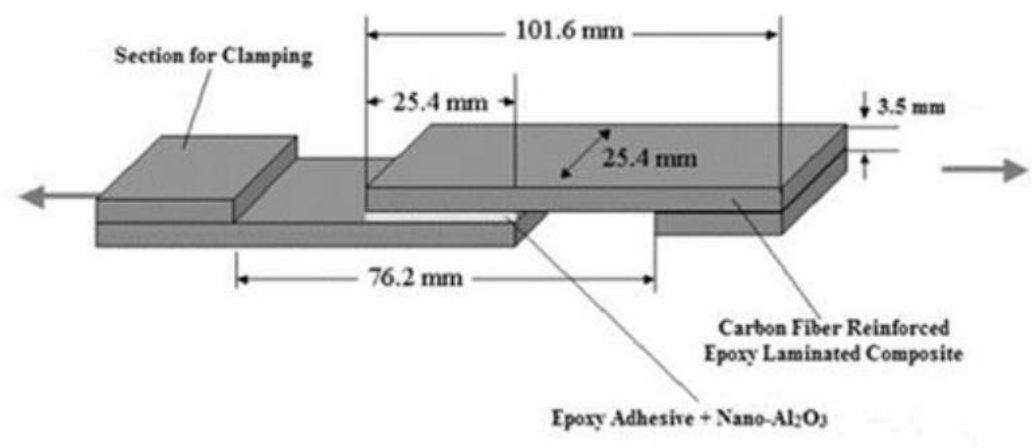

Fig. 2. ASTM-D5868-01 Standard of the shear test

\section{RESULTS AND DISCUSSIONS}

\subsection{Tensile Tests of Epoxy Adhesives}

Tensile tests were performed to understand the effect of modification of epoxy adhesive. These tests were performed according to ASTM D3039 / D3039M. Tensile stress-strain curves of modified epoxy with as a function of different weight percentages of nano-CaCO3 in the adhesive showed in Fig. 3. It is clearly seen in Fig.3, elongation of epoxy and tensile strength behavior show noticeable change. The $2 \mathrm{wt} \%$ nano CaCO3-Epoxy adhesive shows most efficient nanoparticle loading when it compared with the 0 wt\% nano $\mathrm{CaCO}$-Epoxy adhesive.

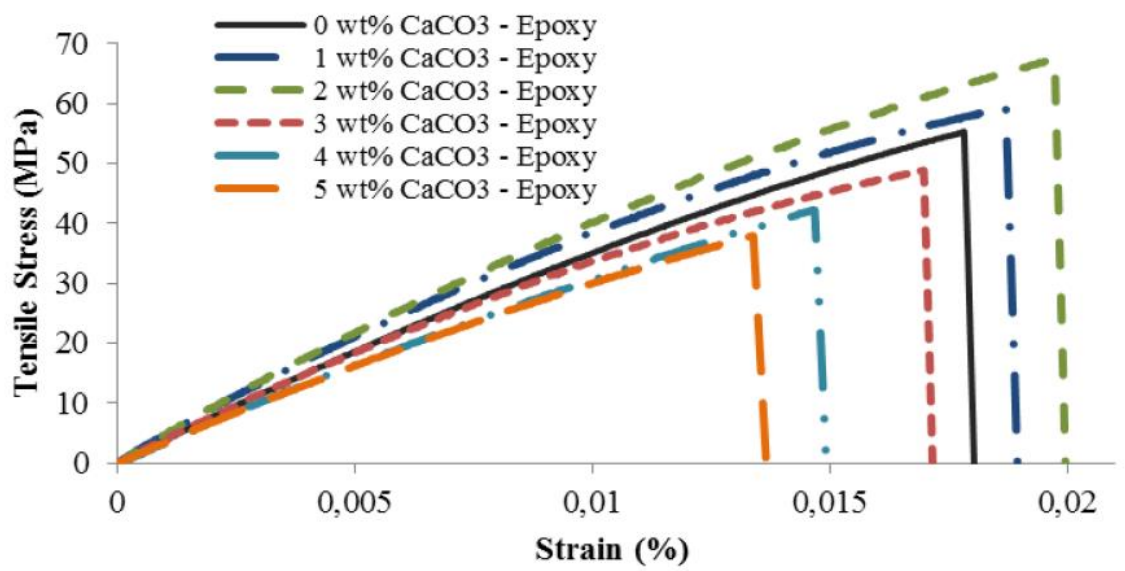

Fig. 3. Load displacement curves of Calcium Carbonate -Epoxy adhesives with different nano-CaCO3 contents (Ulus, 2016)

Table 1 summarizes the tensile properties values of modified and unmodified epoxy adhesives. The tensile strain and strengths were determined from the maximum stress or strain point.

Table 1. The strength and strain value at the peak loads (Ulus, 2016)

\begin{tabular}{|c|l|l|l|}
\hline Material & $\begin{array}{l}\text { Strength } \\
(\mathbf{M P a})\end{array}$ & $\begin{array}{l}\text { Strain } \\
(\mathbf{m m} / \mathbf{m m})\end{array}$ & $\begin{array}{l}\text { Increase } \\
(\mathbf{M P a} \%)\end{array}$ \\
\hline 0 wt\% CaCO3 - Epoxy & 53,47 & $55.3 \pm 1.8$ & - \\
\hline 1 wt\% CaCO3 - Epoxy & 64,23 & $59.2 \pm 2.6$ & 20 \\
\hline 2 wt\% CaCO3 - Epoxy & 71,65 & $67.6 \pm 2.3$ & 34 \\
\hline 3 wt\% CaCO3 - Epoxy & 60,40 & $48.7 \pm 2.5$ & 13 \\
\hline 4 wt\% CaCO3 - Epoxy & 43,22 & $42.3 \pm 3.2$ & -19 \\
\hline 5 wt\% CaCO3 - Epoxy & 35,70 & $37.8 \pm 4.1$ & -33 \\
\hline
\end{tabular}




\subsection{Tensile lap shear tests of Epoxy Adhesives}

Tensile lap shear tests were carried out according to ASTM-D5868-01 standard. It can be seen in Fig.4. that shear load and shear displacement of the $2 \mathrm{wt} \%$ nano $\mathrm{CaCO} 3$-Epoxy/CF adhesive was determined optimum concentration.

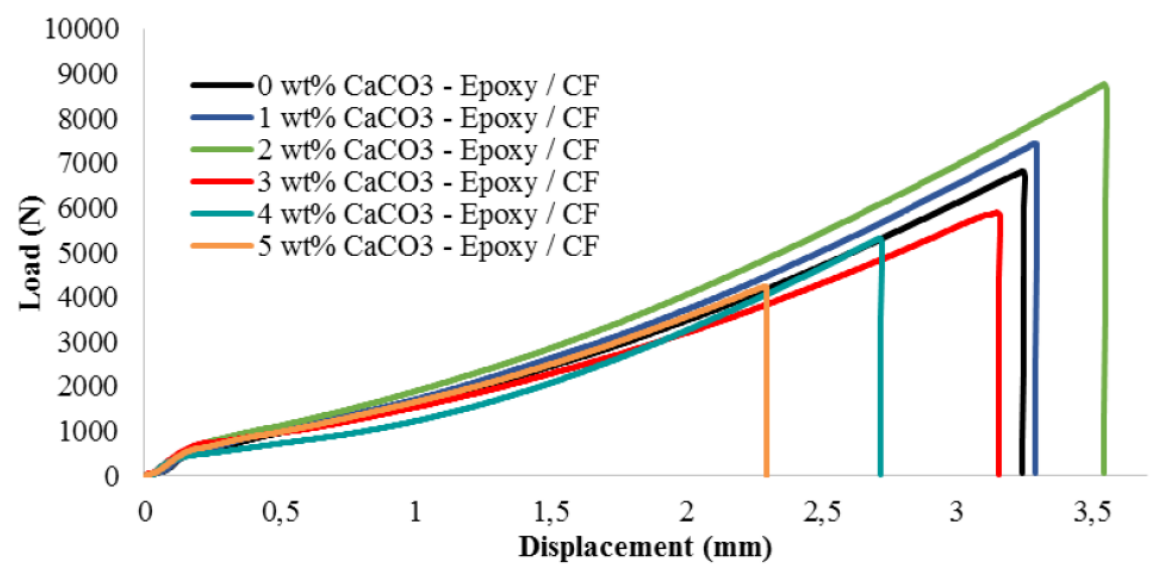

Fig.4. Load-displacement curves of Calcium Carbonate-Epoxy/CF adhesives with different nano- $\mathrm{CaCO} 3$ contents

Table 2 shows the results of the tensile lap shear tests. The shear displacement and shear load were determined from the maximum load or displacement point.

Table 2. The load and displacement value at the peak loads.

\begin{tabular}{|l|l|l|l|}
\hline Material & Load (N) & Displacement (mm) & $\begin{array}{l}\text { Increase } \\
\text { (N \%) }\end{array}$ \\
\hline $0 \mathrm{wt} \% \mathrm{CaCO} 3$ - Epoxy & 6819 & 3,25 & - \\
\hline $1 \mathrm{wt} \% \mathrm{CaCO}$ - Epoxy & 7439 & 3,30 & 9 \\
\hline $2 \mathrm{wt} \% \mathrm{CaCO}$ - Epoxy & 8760 & 3,6 & 28 \\
\hline $3 \mathrm{wt} \% \mathrm{CaCO}$ - Epoxy & 5890 & 3,16 & -13 \\
\hline $4 \mathrm{wt} \% \mathrm{CaCO}$ - Epoxy & 5318 & 2,72 & -22 \\
\hline $5 \mathrm{wt} \% \mathrm{CaCO}$ - Epoxy & 4249 & 2,30 & -37 \\
\hline
\end{tabular}

\subsection{Optical Microscope Examination}

Adhesive bonding surfaces of different samples are shown in the Fig.5. It is clearly observed that optic micrograph of neat adhesive surface exhibits. The adhesive surface for the $0 \mathrm{wt} \%$ nano CaCO3-Epoxy is described in Fig. 5(a) which reveals a brittle behavior characterized by distinctive epoxy cracking. Nevertheless, 2 wt $\%$ CaCO3-Epoxy adhesive surface displays deformation evidence based on more roughly adhesive surface in Fig. 5(b). Besides, fiber bundle breakage sighted seriously on the bonding surface. It can be clearly understand that having added in Epoxy/CF composite, 2 wt\% CaCO3 nanoparticles are boosted toughening mechanism on adhesive surface.
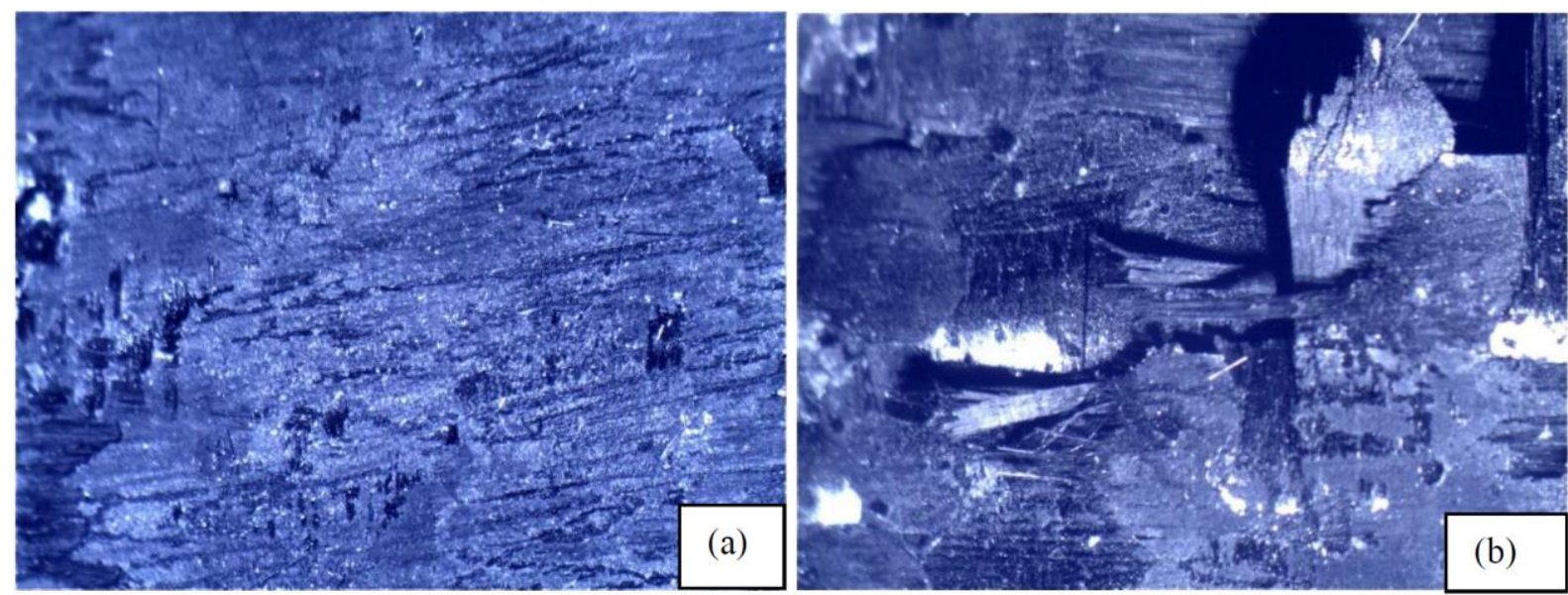

Fig.5. Optic micrographs of adhesive surface a) Epoxy/CF b) 2 wt $\% \mathrm{CaCO} 3$ - Epoxy/CF 


\subsection{Analysis of SEM Images}

The toughening influences of nano-CaCO3 were survey to understand in fracture surfaces of nanocomposite specimens. The SEM micrographs of $2 \mathrm{wt} \%$ nano-CaCO3 in the epoxy matrix are shown in Fig.6. The fracture morphology of the $2 \mathrm{wt} \% \mathrm{CaCO} 3-\mathrm{Epoxy}$ specimen shows very homogenous nanoparticle dispersion.

There are a number of toughening mechanisms in literature which can be associated to the amount of energy absorbed and fracture toughness increases as the main toughening mechanisms are crack deflection, crack pinning, debonding and pull-out (Opelt, 2016; Wetzel, 2006; Zhou and Ruan, 2007; Wagner, 2013; Johnsen, 2007). The fracture surfaces of the composites after the shear test were analyzed by SEM and the results are shown in Fig.7. Micrographs show a clear difference fiber pull-out in 0 wt\% CaCO3Epoxy/CF farther than $2 \mathrm{wt} \% \mathrm{CaCO}$-Epoxy/CF in Fig.7 (a)-(b). This deduction indicates that interaction of fiber-matrix in neat

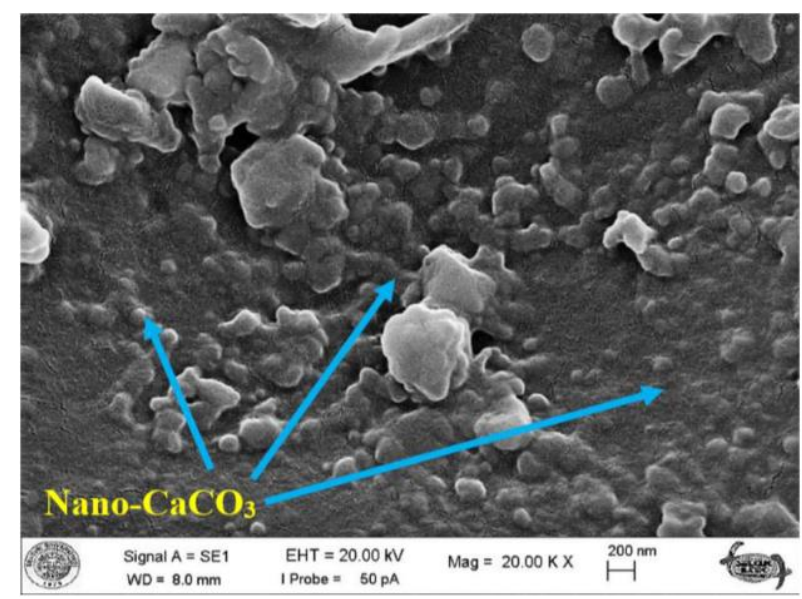

Fig.6. Dispersion of nano-CaCO3

Epoxy/CF is weak. Besides, plastic deformation in the nano modified $2 \mathrm{wt} \% \mathrm{CaCO} 3-\mathrm{Epoxy} / \mathrm{CF}$ more than 0 wt\% CaCO3Epoxy/CF in the fiber gap surfaces. Therefore, the toughness of $2 \mathrm{wt} \% \mathrm{CaCO}$-Epoxy/CF higher than $0 \mathrm{wt} \% \mathrm{CaCO}$-Epoxy/CF.
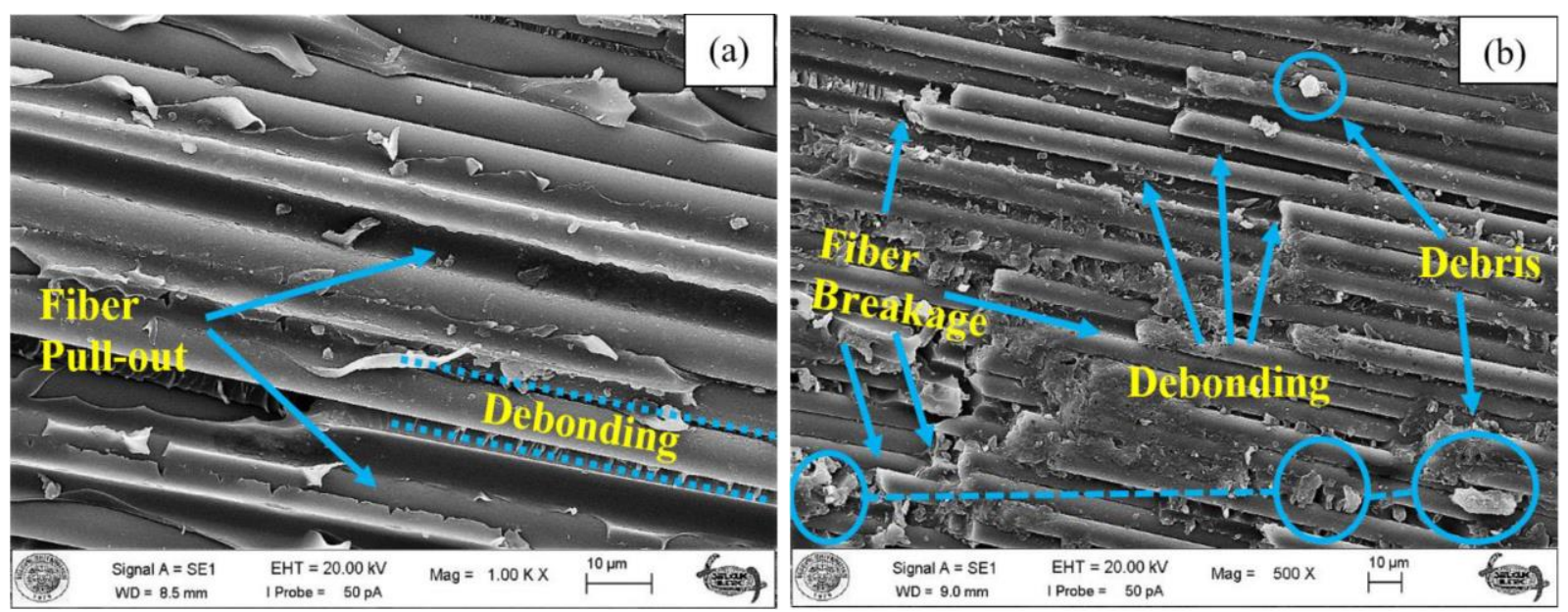

Fig.7. Micrographs of fracture surface: (a) 0 wt $\% \mathrm{CaCO} 3-\mathrm{Epoxy} / \mathrm{CF}$ (b) $2 \mathrm{wt} \% \mathrm{CaCO} / \mathrm{Epoxy} / \mathrm{CF}$

\section{CONCLUSION}

In this paper, nano-CaCO3-Epoxy mixture were prepared with different nanoparticle loading and the effects of nano particle adding on epoxy adhesive were investigated. Experimental results show that the $2 \mathrm{wt} \%$ nano $\mathrm{CaCO} 3$ modification significantly improved epoxy adhesive strength by $28 \%$. The optic microscopy investigate revealed that the adhesive surfaces had different morphologies. This differences and nanoparticle effect which are observed via SEM are associated with adhesives strength increasement. The results of the conducted experiments show that the nano $\mathrm{CaCO} 3$ modification in epoxy resin enhance adhesive properties of nanocomposites. The adhesions of the fiber - matrix and interlaminar in the $0 \mathrm{wt} \% \mathrm{CaCO} 3$ - Epoxy matrix are determined as weaker than that of the modified $2 \mathrm{wt} \% \mathrm{CaCO} 3 /$ Epoxy matrix. Fracture surface micrographs revealed that the relationship between strength increasement and toughening behaviours. 


\section{REFERENCES}

Fu YX, He ZX, Mo DC and Lu SS, (2014). "Thermal conductivity enhancement of epoxy adhesive using graphene sheets as additives", International Journal of Thermal Sciences, 86, 276-283.

Kaybal, H.B., Ulus H., Avci A., (2016). "Tensile Properties Improvement of Nano CaCO3 Reinforced Epoxy Nanocomposites" 16 th. International Materials Symposium (IMPS'16), 12-14 October 2019, Denizli, Turkey.

Jeong WJ, Nishikawa H, Itou D and Takemoto T, (2005). "Electrical characteristics of a new class of conductive adhesive". Materials transactions, 46(10), 2276-2281

Jiang H, Moon KS, Lu J and Wong CP, (2005) "Conductivity enhancement of nano silver-filled conductive adhesives by particle surface functionalization”, Journal of electronic materials, 34(11), 1432-1439.

Johnsen BB, Kinloch AJ, Mohammed RD, Taylor AC, Sprenger S, (2007). "Toughening mechanisms of nanoparticle-modified epoxy polymers", Polymer, 48; 530-541.

Khoee S and Hassani N, Adhesion, (2010). Strength improvement of epoxy resin reinforced with nanoelastomeric copolymer, Materials Science and Engineering: A, 527(24), 6562-6567.

Kim DH and Kim HS, (2013). "Waterproof characteristics of nanoclay/epoxy nanocomposite in adhesively bonded joints". Composites Part B: Engineering, 55, 86-95.

Lu D and Wong CP, (2000),'Development of conductive adhesives for solder replacement”, Components and Packaging Technologies, IEEE Transactions on, 23(4), 620-626.

Murakami S, Sekiguchi Y, Sato C, Yokoi E and Furusawa T, (2015). "Strength of cylindrical butt joints bonded with epoxy adhesives under combined static or high-rate loading", International Journal of Adhesion and Adhesives.

Opelt CV and Coelho LA, (2016). "Reinforcement and toughening mechanisms in polymer nanocomposites-Reinforcement effectiveness and nanoclay nanocomposites". Materials Chemistry and Physics, 169, 179-185.

Sydlik SA, Lee JH, Walish JJ, Thomas EL and Swager TM, (2013). "Epoxy functionalized multi-walled carbon nanotubes for improved adhesives". Carbon, 59, 109-120.

Tan F, Qiao X, Chen J and Wang H, (2006). "Effects of coupling agents on the properties of epoxy-based electrically conductive adhesives", International journal of adhesion and adhesives, 26(6), 406-413.

Tee DI, Mariatti M, Azizan A, See CH and Chong KF, (2007). "Effect of silane-based coupling agent on the properties of silver nanoparticles filled epoxy composites". Composites Science and Technology, 67(11), 2584-2591.

Tüzün FN and Tunalığlu MŞ, (2015). "The effect of finely-divided fillers on the adhesion strengths of epoxy-based adhesives”, Composite Structures, 121, 296-303.

Ulus H, Üstün T, Şahin, ÖS, Karabulut SE., Eskizeybek V, and Avc1 A, (2015). "Low-velocity impact behavior of carbon fiber/epoxy multiscale hybrid nanocomposites reinforced with multiwalled carbon nanotubes and boron nitride nanoplates". Journal of Composite Materials, DOI: 0021998315580835.

Wagner HD, Ajayan PM and Schulte K, (2013). "Nanocomposite toughness from a pullout mechanism". Composite Science Technology, 83: 27-31.

Wetzel B, Rosso P, Haupert F and Friedrich K, (2006). "Epoxy nanocomposite fracture and toughening mechanisms”, Engineering Fracture Mechanics, 73: 2375-2398.

Wu HP, Liu JF, Wu XJ, Ge MY, Wang Y W, Zhang G.Q. and Jiang JZ, (2006). "High conductivity of isotropic conductive adhesives filled with silver nanowires", International journal of adhesion and adhesives, 26(8), 617-621.

Xian G, Walter R, and Haupert F, (2006). "Friction and wear of epoxy/TiO 2 nanocomposites: Influence of additional short carbon fibers Aramid and PTFE particles”, Composites Science and Technology, 66(16), 3199-3209.

Zhang R, Moon KS, Lin W and Wong CP, (2010). "Preparation of highly conductive polymer nanocomposites by low temperature sintering of silver nanoparticles". Journal of Materials Chemistry, 20(10), 2018-2023. 
Zhou TH, WH Ruan, Rong MZ, Zhang MQ and Mai YL, (2007). Keys to toughening of non-layered Nanoparticles/Polymer composites, Adv. Mater (19); 2667-2671. 